\title{
Smoking: the most preventable disease
}

\author{
Robert W Schrier
}

Smoking dramatically affects the morbidity and mortality associated with cancer, cardiovascular disease and pulmonary disease. Less is known about the deleterious effects of smoking on the kidney; however, we do know that these effects extend beyond diabetic renal disease to various other forms of kidney dysfunction (Orth SR [2002] J Am Soc Nephrol 13: 1663-1672). A focus on smoking prevention in developed countries has resulted in a substantial decrease in the prevalence of this habit.

In recent years, however, the tobacco industry has been focusing on expanding its markets in developing countries. The $\mathrm{WHO}$ predicts that by $2020,70 \%$ of deaths resulting from smokingrelated illnesses will occur in developing countries (Wright AA and Katz IT [2007] N Engl J Med 356: 1493-1496). One-third of the world's smokers now live in China; smoking-related diseases cause more than 1 million deaths a year in that country. Despite owning the largest cigarette monopoly in the world (China National Tobacco), the government of China, together with those of 145 other countries, ratified the WHO Framework Convention on Tobacco Control. The Framework includes proven preventative strategies, such as restricting smoking in public places, limiting advertising of tobacco products, passing and enforcing laws against children and adolescents buying cigarettes, raising taxes on tobacco products, printing health warning labels on tobacco products, and other educational programs. The US is one of the countries that has not ratified this WHO treaty.

The governments of developing countries reap major tax benefits from cigarette sales and, therefore, cannot be depended upon
... professional

medical

societies

need to be

aggressively

involved in the

fight against

tobacco use

via .... the

formation of an

international

consortium ...

$R W$ Schrier is Editorin-Chief of Nature

Clinical Practice

Nephrology.

\section{Competing interests}

The author declared he has no competing interests.

www.nature.com/clinicalpractice doi:10.1038/ncpneph0527 to aggressively address this enormous and preventable health problem. In 2005, taxes and profits from cigarette sales in China generated US $\$ 32.5$ billion, approximately $7.6 \%$ of the government's total revenues (Wright AA and Katz IT [2007] N Engl J Med 356: 1493-1496). Thus, professional medical societies need to be aggressively involved in the fight against tobacco use via, for example, the formation of an international consortium of cardiology, pulmonology, oncology and nephrology societies. This approach would be an appropriate focus for World Kidney Day 2008.

While one day of international campaigning can be a catalyst for change, professional societies such as the International Society of Nephrology must wage an ongoing war against tobacco use. There are 1.5 billion smokers worldwide, the majority of whom desire to quit. Nephrologists should join other health professionals throughout the world in supporting smoking cessation and smoking prevention programs. Asia, where two-thirds of the world's population lives, is at risk for future expansion of tobacco use. In Asia, over $50 \%$ of males smoke, compared with only $5-10 \%$ of women and children. Unfortunately, this statistic means that women and children in Asia are a large potential market for expansion of the smoking epidemic (Bartecchi CE et al. [1995] Sci Am 272: 44-51). Health-care professionals, including nephrologists and their societies, must be aware of the growing tobacco epidemic in the developing world and be actively involved, together with their patients and governments, in fighting this preventable mass killer. 